\title{
Analytical Evaluation of Omega 3 Fatty Acids Imbedded in Hydrophobic Starch in the Rumen
}

\author{
Malcolm Ballard \\ The Ballard Group, Inc., Cincinnati, OH, USA \\ Email: malcolm.ballard@tbgnutrition.com
}

How to cite this paper: Ballard, M. (2018) Analytical Evaluation of Omega 3 Fatty Acids Imbedded in Hydrophobic Starch in the Rumen. Open Journal of Animal Sciences, 8, 432-438.

https://doi.org/10.4236/ojas.2018.84032

Received: September 4, 2018

Accepted: October 20, 2018

Published: October 23, 2018

Copyright $\odot 2018$ by author and Scientific Research Publishing Inc. This work is licensed under the Creative Commons Attribution International License (CC BY 4.0).

http://creativecommons.org/licenses/by/4.0/

(c) (i) Open Access

\begin{abstract}
Two experiments were conducted to assess the value of hydrophobic starch as a method to encapsulate a supplement consisting of refined fish oil intended for use as a feed supplement for ruminant animals. In Study 1, the product was incubated in vitro for 24 hours. The entire media was analyzed to determine fatty acid composition. In Study 2, the test material was incubated for 0 , $2,4,6,8,10,12$ and 24 hours in order to determine rate of loss of dry matter, as well as the fatty acid profile of the dry matter remaining at 24 hours. Results from Study 1 indicated that $61.1 \%$ of the eicosapentaenoic acid (C20:5) and $75.3 \%$ docosahexaenoic acid (C22:6) were still intact after the 24 hour incubation period. In Study 2, 39.1\% of the test material was solubilized in the 24 hour period. However, the losses in C20:5 and C22:6 fatty acids were less (25.32\% and $27.90 \%$ respectively) indicating that the majority of the test product was protected against biohydrogenation. It was concluded that hydrophobic starch can be used to ruminally protected fish oil and to deliver C20:5 and C22:6 fatty acids past the rumen.
\end{abstract}

\section{Keywords}

Encapsulation Omega-3, Rumen-Protection

\section{Introduction}

Linoleic acid (C18:2) the first member of the omega 6 family and linolenic acid (C18:3), the corresponding first member of the omega 3 family, are considered to be essential fatty acids [1] as these two essential fatty acids can be elongated and desaturated to form the highly unsaturated fatty acids (HUFA). Omega 3 and omega 6 HUFA are the precursors of vital lipid mediators; the eicosanoids which in turn give rise to other important signaling compounds such as prostaglandins and leukotrienes [2]. Oddly enough the omega 3 and omega 6 fatty 
acids are elongated and desaturated using the same enzyme systems, yet have apposing biological effects [3]. Because of this it is possible to have insufficient amounts of HUFA from one family if the enzyme system is overwhelmed by fatty acids from the other, with this generally occurring with the omega 3 family of fatty acids [4] [5].

Marine oils are rich sources of omega 3 fatty acids, most notably eicosapentaenoic acid (C20:5) and docosahexaenoic acid (C22: 6). The dietary provision of marine oils insures the availability of $\mathrm{C} 20: 5$ and $\mathrm{C} 22: 6$ in the diet for non-ruminant animals. However with ruminants, these fatty acids undergo biohydrogenation in the rumen. Kairenius et al. [6] recovered numerous trans- and cis2 20 and 22 carbon length fatty acids from abomasally cannulated cows that had received a diet supplemented with fish oil. However, only $1.13 \%$ of the C20:5 and $0.87 \%$ of the C22:6 fatty acids appeared after the rumen. Similarly, Shingfield et al. [7] reported that $93.1 \%-96.7 \%$ of the C20:5 and $91.6 \%-95.8 \%$ of the C22:6 were biohydrogenated in the rumen of steers.

A number of factors may influence the extent of biohydrogenation of fatty acids in the rumen. First, the fat must undergo lipolysis. Lipolysis rates may decline as dietary lipid increases, particularly if the source is high in unsaturated fatty acids which tend to be more harmful to rumen bacteria [8]. Rumen $\mathrm{pH}$ can likewise have an effect on the extent of biohydrogenation [9]. Fierez et al. [10] also noted that there are differences from lab to lab with respect to donor animal diets, adaptation of donor animals, amount of inoculum used in culture media and atmospheric gas that can result in some across laboratory variability. However, even under such varying conditions, the extent of biohydrogenation remains high, with little of these important fatty acids available to the animal to incorporate in tissues.

Lanier and Corl [11] noted that, in spite of the need for a reliable source of supplemental HUFA, a practical vehicle to provide these fatty acids was not available. A number of rumen protected nutrients, such as amino acids, have been successfully developed, and these largely rely upon either a lipid matrix or a lipid coating. Lipid coatings are not logical choices for HUFA, as the HUFA would mix with the coating, reduce melting point of the final product, and severely reduce the effectiveness of the coating. While calcium salts of fatty acids generally reduce the biohydrogenation of fatty acids, they do not adequately protect C20:5 and C22:6 [12]. An alternative approach is to use a hydrophobic starch to protect the lipid from lipolysis and solubilization in the rumen. This research involved determining the extent of protection that can be provided by a product prepared from fish oil surrounded by a hydrophobic starch matrix.

\section{Materials and Methods}

The product evaluated in these investigations (Salmate, the Ballard Group, Cincinnati, OH, USA, Table 1) consisted of refined fish oils, vitamin $\mathrm{E}$ and hydrophobic starch. The product is made by flash freezing micro particles of the 
Table 1. Guideline composition of the product tested.

\begin{tabular}{cc}
\hline Item & Value \\
\hline Particle size, uM & $<50$ \\
Lipid, \% & 45 \\
Starch, \% & 55 \\
C20:5 (EPA), \% of fatty acids & 7.3 \\
C22:6 (DHA), \% of fatty acids & 10.9 \\
Bulk density, g/ml & 0.493
\end{tabular}

oil/vitamin E mixture, suspended in air fluidized bed spray drying technique, with the resulting particles less than $50 \mathrm{uM}$ in diameter [13].

Because of the small particle size, rumen in sacco testing was not possible, as the particles were smaller than the pore openings in the bags. Therefore two independent laboratories with two different testing procedures were engaged to assess the integrity of the matrix with respect to rumen protection of HUFA.

\subsection{Study 1}

This experiment was conducted at the Atlantic Dairy and Forage Institute, New Brunswick, Canada. Rumen fluid was obtained from 2 non-lactating cows, filtered through 3 layers of cheese cloth and flushed with carbon dioxide gas. Six 250 Erlenmeyer flasks/treatment, containing $30 \mathrm{ml}$ of strained rumen fluid and $30 \mathrm{ml}$ of McDougall's buffer solution [14] were adjusted to $\mathrm{pH} 7.0$ and maintained at 37 degrees in a shaking water bath. Treatments were $250 \mathrm{mg}$ wheat starch/flask (control) and $250 \mathrm{mg} /$ flask of the test product. Flasks were stoppered and a one-way gas release valve was attached.

After $24 \mathrm{~h}$ of incubation, two $10 \mathrm{ml}$ aliquots of fluid were pipetted from each flask while samples were being stirred on a magnetic stirrer under a stream of carbon dioxide gas. These subsamples were freeze-dried, methylated, and fatty acid methyl esters were extracted with hexane [15]. Gas chromatography was used to determine fatty acid profiles. The fatty acid C13:0 was added as an internal standard.

\subsection{Study 2}

This experiment was conducted at Sana Dam Pars Research and Development, Tehran, Iran. Rumen fluid was collected from two rumen cannulated sheep maintained on an all forage diet. Fresh rumen fluid was homogenized in a blender for 1 minute under carbon dioxide, then filtered through 4 layers of cheesecloth. The rumen fluid filtrate was added to incubation bottles containing the test product, flushed with carbon dioxide gas and placed in a water bath at 37 degrees. Flasks (two per time period) were removed at 0, 2, 4, 6, 8, 12 and $24 \mathrm{~h}$, and dry matter recovery was determined. Rate of loss of dry matter was determined using the procedure of Orskov and McDonald [16]. Fatty acid composi- 
tion of the original material and the fatty acid composition of samples incubated for 24 hours were determined using the same methods as outlined in Study 1.

\section{Results}

\subsection{Study 1}

This trial provided information on the extent of biohydrogenation of the test product after incubation for a period of $24 \mathrm{~h}$. Control samples, containing starch were evaluated to determine if any omega 3 fatty acids were generated by the rumen microbes in the absence of the fish oil additive.

The fatty acid profiles of the original sample, as well as the samples containing starch alone or the Salmate product are provided in Table 2. Results indicate that no omega 3 fatty acids were produced in the rumen fluid used in the study, and the only source was therefore of test sample origin. These results showed that $61 \%$ and $75 \%$ of the C20:5 and C22:6 fatty acids remained protected after 24 hours.

\subsection{Study 2}

This trial measured the rate of loss of dry matter from the test product (Table 3) during incubation. The results showed that at least $62.1 \%$ of the total sample would be expected to leave the rumen intact. The fatty acid composition of the sample before and after incubation is provided in Table 4. Although this calculation underestimates the test material that escapes the rumen by not including any of the "b" fraction from Table 2 that may escape the rumen, it still suggests that a substantial portion of the unsaturated fatty acids were protected by the coating material. In particular, the omega 3 fatty acids (C18:3, C20:5 and C22:6) largely remained in the fractioned destined to escape fermentation.

Table 2. Fatty acid composition (\% of total fatty acids) of the media, test material, and samples of wheat starch and test product after $24 \mathrm{~h}$ of incubation in vitro.

\begin{tabular}{ccccc}
\hline \multirow{2}{*}{ Fatty Acid, \% } & Pre-incubation & \multicolumn{2}{c}{ Post Incubation } & Remaining, ${ }^{1}$ \\
\cline { 2 - 4 } & Test & Control & Test & 84.67 \\
\hline C14:0 & 6.39 & 2.13 & 5.41 & 100.65 \\
C15:0 & 0.43 & 1.85 & 0.43 & 113.88 \\
C16:0 & 16.68 & 24.75 & 18.99 & 87.03 \\
C16:1 & 7.75 & 0.00 & 6.74 & 135.26 \\
C18:0 & 3.64 & 46.27 & 4.93 & 132.94 \\
C18:1 & 23.47 & 0.00 & 31.21 & 58.47 \\
C18:2 & 5.18 & 2.48 & 3.03 & 117.22 \\
C18:3 & 0.82 & 0.00 & 0.96 & 61.12 \\
C20:5 & 7.31 & 0.00 & 4.47 & 75.31 \\
C22:6 & 10.90 & 0.00 & 8.23 & \\
\hline
\end{tabular}

${ }^{1}$ Postincubation test/pre-incubation test $\times 100$. 
Table 3. Rates of disappearance of test material in vitro ${ }^{1}$.

\begin{tabular}{cc}
\hline Parameter & Value \\
\hline a, $\%$ & 12.0 \\
b, $\%$ & 37.9 \\
c, $\%$ & 62.1 \\
r, portion/hour & 0.073
\end{tabular}

"a" is initial solubility at zero time, "b" the quantity that will potentially disappear at rate $r /$ hour and "c" is the fraction of non-soluble dry matter will escape the rumen [16].

Table 4. Rates of disappearance of test material in vitro ${ }^{1}$.

\begin{tabular}{ccccc}
\hline Fatty Acid, \% & Initial & Final & Corrected $^{\mathrm{a}}$ & ${\text { Remaining, }{ }^{2}}^{2}$ \\
\hline C14:0 & 4.70 & 4.32 & 2.68 & 57.08 \\
C16:0 & 18.34 & 16.32 & 10.13 & 55.26 \\
C16:1 & 5.50 & 4.20 & 2.61 & 47.42 \\
C18:0 & 5.21 & 6.68 & 4.15 & 79.62 \\
C18:1 & 16.73 & 17.05 & 10.59 & 63.29 \\
C18:2 & 17.30 & 18.33 & 11.38 & 65.80 \\
C18:3 & 3.95 & 4.60 & 2.86 & 72.32 \\
C20:5 (EPA) & 7.90 & 9.50 & 5.90 & 74.68 \\
C22:6 (DHA) & 11.80 & 13.70 & 8.51 & 72.10 \\
\hline
\end{tabular}

${ }^{1}$ Corrected for recovered dry matter (final fatty acids $\times 62.1 / 100$ ); ${ }^{2}$ Corrected fatty acids/initial fatty acids $\times$ 100.

\section{Discussion}

When fish oils are provided to ruminant animals, the 20:5 and 22:6 fatty acids have been demonstrated to be extensively biohydrogenated and therefore unavailable for metabolism by the ruminant animal. Shingfield et al. [17] determined that only 0.9 and $0.6 \mathrm{~g}$ of C20:5 and C22:6 were recovered at the duodenum in cows consuming 43.5 and $27.7 \mathrm{~g}$ of these two fatty acids. Similarly, in vitro studies have shown that C22:6 is completely hydrogenated [18], but can become toxic to rumen microbes at high concentrations, resulting in reduced lipolysis [18]. This is consistent with the findings of Dohme et al. [19].

Two differing approaches were taken in these experiments to determine the extent to which unsaturated fatty acids, and in particular the important omega 3 fatty acids are biohydrogenated. In the Study 1, aliquots of the total incubation media were analyzed. This method quantified the total fatty acids present. Saturated fatty acids increased with biohydrogenation of corresponding unsaturated fatty acids. However, unsaturated fatty acids were not fully biohydrogenated. In Study 2, only the solid residue remaining after incubation was analyzed. Any fatty acids in solution were not taken into account, and the results would be more likely to underestimate total fatty acids remaining. However, the results 
also showed that protection was afforded by the hydrophobic starch matrix, and unsaturated fatty acids would be expected to leave the rumen intact.

\section{Conclusion}

Although different approaches were taken by the two independent laboratories, the results of these two experiments indicate that between $60 \%-75 \%$ of the C20:5 and 70\% to $75 \%$ of the C22:6 fatty acids in the test product would be expected to escape fermentation, and that the test product can reliably be used to supply omega 3 fatty acids to ruminants.

\section{Conflicts of Interest}

The author declares no conflicts of interest regarding the publication of this paper.

\section{References}

[1] Mattos, R., Staples, C.R. and Thatcher, W.W. (2000) Effects of Dietary Fatty Acids on Reproduction in Ruminants. Reviews of Reproduction, 5, 38-45. https://doi.org/10.1530/ror.0.0050038

[2] Bozza, P.T., Bakker-Abreu, I., Navarro-Xavier, R.A. and Bandeira-Melo, C. (2011) Lipid Body Function in Eicosanoid Synthesis: An Update. Prostaglandins, Leukotrienes and Essential Fatty Acids, 85, 205-213. https://doi.org/10.1016/j.plefa.2011.04.020

[3] Schmitz, G. and Ecker, J. (2008) The Opposing Effects of n-3 and n-6 Fatty Acids. Progress in Lipid Research, 47, 147-155. https://doi.org/10.1016/j.plipres.2007.12.004

[4] Nakamura, M.T. and Nara, T.Y. (2003) Essential Fatty Acid Synthesis and Its Regulation in Mammals. Prostaglandins, Leukotrienes and Essential Fatty Acids, 68, 145-150. https://doi.org/10.1016/S0952-3278(02)00264-8

[5] Simopoulos, A.P. (2002) The Importance of The Ratio of Omega-6/Omega-3 Essential Fatty Acids. Biomedicine \& Pharmacotherapy, 56, 365-379. https://doi.org/10.1016/S0753-3322(02)00253-6

[6] Kairenius, P., Toivonen, V. and Shingfield, K.J. (2011) Identification and Ruminal Outflow of Long-Chain Fatty Acid Biohydrogenation Intermediates in Cows Fed Diets Containing Fish Oil. Lipids, 46, 587-606. https://doi.org/10.1007/s11745-011-3561-1

[7] Shingfield, K.J., Lee, M.R.F., Humphries, D.J., Scollan, N.D., Toivonen, V., Reynolds, C.K. and Beever, D.E. (2010) Effect of Incremental Amounts of Fish Oil in the Diet on Ruminal Lipid Metabolism in Growing Steers. British Journal of Nutrition, 104, 56-66. https://doi.org/10.1017/S0007114510000292

[8] Beam, T.M., Jenkins, T.C., Moate, P.J., Kohn, R.A. and Palmquist, D.L. (2000) Effects of Amount and Source of Fat on the Rates of Lipolysis and Biohydrogenation of Fatty Acids in Ruminal Contents. Journal of Dairy Science, 83, 2564-2573. https://doi.org/10.3168/jds.S0022-0302(00)75149-6

[9] Fuentes, M.C., Calsamiglia, S., Fievez, V., Blanch, M. and Mercadal, D.(2011) Effect of $\mathrm{pH}$ on Ruminal Fermentation and Biohydrogenation of Diets Rich in Omega-3 or Omega-6 Fatty Acids in Continuous Culture of Ruminal Fluid. Animal Feed Science and Technology, 169, 35-45. 
https://doi.org/10.1016/j.anifeedsci.2011.05.013

[10] Fievez, V., Vlaeminck, B., Jenkins, T., Enjalbert, F. and Doreau, M. (2007) Assessing Rumen Biohydrogenation and Its Manipulation in Vivo, in Vitro and in Situ. European Journal of Lipid Science and Technology, 109, 740-756. https://doi.org/10.1002/ejlt.200700033

[11] Lanier, J.S. and Corl, B.A. (2015) Challenges in Enriching Milk Fat with Polyunsaturated Fatty Acids. Journal of Animal Science and Biotechnology, 6, 26. https://doi.org/10.1186/s40104-015-0025-0

[12] Castañeda-Gutiérrez, E., De Veth, M.J., Lock, A.L., Dwyer, D.A., Murphy, K.D. and Bauman, D.E. (2007) Effect of Supplementation with Calcium Salts of Fish Oil on n-3 Fatty Acids in Milk Fat. Journal of Dairy Science, 90, 4149-4156. https://doi.org/10.3168/jds.2006-856

[13] Fuchs, M., Turchiuli, C., Bohin, M., Cuvelier, M.E., Ordonnaud, C., Peyrat-Maillard, M.N. and Dumoulin, E. (2006) Encapsulation of Oil in Powder Using Spray Drying and Fluidised Bed Agglomeration. Journal of Food Engineering, 75, 27-35. https://doi.org/10.1016/j.jfoodeng.2005.03.047

[14] McDougall, E.I. (1948) Studies on Ruminant Saliva. 1. The Composition and Output of Sheep's Saliva. Biochemical Journal, 43, 99-109.

https://doi.org/10.1042/bj0430099

[15] Kramer, J.K., Fellner, V., Dugan, M.E., Sauer, F.D., Mossoba, M.M. and Yurawecz, M.P. (1997) Evaluating Acid and Base Catalysts in the Methylation of Milk and Rumen Fatty Acids with Special Emphasis on Conjugated Dienes and Total trans Fatty Acids. Lipids, 32, 1219-1228. https://doi.org/10.1007/s11745-997-0156-3

[16] Ørskov, E.R. and McDonald, I. (1979). The Estimation of Protein Degradability in the Rumen from Incubation Measurements Weighted according to Rate of Passage. The Journal of Agricultural Science, 92, 499-503. https://doi.org/10.1017/S0021859600063048

[17] Shingfield, K.J., Ahvenjärvi, S., Toivonen, V., Ärölä, A., Nurmela, K.V.V., Huhtanen, P. and Griinari, J.M. (2003) Effect of Dietary Fish Oil on Biohydrogenation of Fatty Acids and Milk Fatty Acid Content in Cows. Animal Science, 77,165-179.

[18] Klein C. (2011) Biohydrogenation of Docosahexaenoic Acid. Ph.D. Thesis, Clemson University, Clemson.

[19] Dohme, F., Fievez, V., Raes, K. and Demeyer, D.I. (2003) Increasing Levels of Two Different Fish Oils Lower Ruminal Biohydrogenation of Eicosapentaenoic and Eocosahexaenoic Acid in Vitro. Animal Research, 52, 309-320. https://doi.org/10.1051/animres:2003028 